\title{
Manipulating Connexin Communication Channels: Use of Peptidomimetics and the Translational Outputs
}

\author{
W. Howard Evans · Geert Bultynck • \\ Luc Leybaert
}

Received: 14 May 2012/ Accepted: 7 July 2012/Published online: 11 August 2012

(C) The Author(s) 2012. This article is published with open access at Springerlink.com

\begin{abstract}
Gap junctions are key components underpinning multicellularity. They provide cell to cell channel pathways that enable direct intercellular communication and cellular coordination in tissues and organs. The channels are constructed of a family of connexin (Cx) membrane proteins. They oligomerize inside the cell, generating hemichannels (connexons) composed of six subunits arranged around a central channel. After transfer to the plasma membrane, arrays of $\mathrm{Cx}$ hemichannels (CxHcs) interact and couple with partners in neighboring attached cells to generate gap junctions. Cx channels have been studied using a range of technical approaches. Short peptides corresponding to sequences in the extra- and intracellular regions of Cxs were used first to generate epitopespecific antibodies that helped studies on the organization and functions of gap junctions. Subsequently, the peptides themselves, especially Gap26 and -27, mimetic peptides derived from each of the two extracellular loops of connexin43 (Cx43), a widely distributed $\mathrm{Cx}$, have been extensively applied to block $\mathrm{Cx}$ channels and probe the biology of cell communication. The development of a further series
\end{abstract}

Dedicated to the memory of Tudor Griffith, 1951-2011.

W. H. Evans $(\square)$

Institute of Infection and Immunity, Cardiff University School of Medicine, Heath Park, Cardiff, Wales CF14 4XN, UK e-mail: EvansWH@cf.ac.uk

G. Bultynck

Department of Cellular and Molecular Medicine, K. U. Leuven Campus Gasthuisberg, 3000 Leuven, Belgium

L. Leybaert

Department of Basic Medical Sciences, Physiology Group, Faculty of Medicine and Health Science, Ghent University, Ghent, Belgium of short peptides mimicking sequences in the intracellular loop, especially the extremity of the intracellular carboxyl tail of Cx43, followed. The primary inhibitory action of the peptidomimetics occurs at $\mathrm{CxHcs}$ located at unapposed regions of the cell's plasma membrane, followed by inhibition of cell coupling occurring across gap junctions. CxHcs respond to a range of environmental conditions by increasing their open probability. Peptidomimetics provide a way to block the actions of CxHcs with some selectivity. Furthermore, they are increasingly applied to address the pathological consequences of a range of environmental stresses that are thought to influence $\mathrm{Cx}$ channel operation. $\mathrm{Cx}$ peptidomimetics show promise as candidates in developing new therapeutic approaches for containing and reversing damage inflicted on CxHcs, especially in hypoxia and ischemia in the heart and in brain functions.

Keywords Connexin hemichannels - Peptidomimetics . Clinical translation

\section{Introduction}

Gap junctions are cell-cell connections that ensure harmonious integration, regulation and equalization of metabolic events and signaling in tissues and organs. Their role in the coordination of cell behavior is vividly illustrated in the heart, where gap junctions in the intercalated discs provide pathways that allow direct intercellular electrical communication essential for synchronous contraction of component myocytes and for generating waves of rhythmic contractions observed in arteries. Gap junctions are constructed of paired connexin hemichannels (CxHcs), each composed of six protein subunits arranged around a central pore, and occur at adhesive areas where plasma membranes 
touch. Hcs are continuously recruited from surrounding unapposed plasma membrane areas and subsequently dock head to head with partners from adjacent cells and attach to the rims of preexisting gap junction plaques. The operational area and size of gap junction plaques where intercellular communication occurs are regulated by a balanced internalization and degradation of the dodecameric $\mathrm{Cx}$ channel units (Laird 2006; Goodenough and Paul 2009).

Many approaches have been applied to study the structure and function of gap junctions and their constituent CxHcs (Harris and Locke 2009). This account deals with the development of peptides that correspond to specific short $\mathrm{Cx}$ sequences that block widely the operation of gap junctions and CxHcs. The consequences ensuing from the actions of these peptides on $\mathrm{Cx}$ channels are allowing research to move forward into the realms of translational innovation across many fronts, especially in addressing the pathological consequences of ischemic stress that induces the channels to become leaky. Peptidomimetic approaches are complemented by gene knockout and antisense siRNA approaches to study Cx-based communication.

The development and application of short peptides mimicking sequences in various protein domains of Cxs, especially $\mathrm{Cx} 43$, initially focused on the two loops projecting outside the cell membrane; but peptides corresponding to sequences in the cytoplasmic intracellular loop and carboxyl tail are now finding application. Over the last 25 years, mimetic peptides have become important tools in elucidating a panoply of roles for gap junctions and their constituent $\mathrm{CxHcs}$ in a wide range of cells, tissues and organs. These are summarized in Tables 1, 2 and 3.

\section{Development and Exploitation of Cx Mimetic Peptides}

Following the deduction of the complete amino acid sequences especially of $\mathrm{Cx} 32$ and $\mathrm{Cx} 43$, two of the 20 members of the $\mathrm{Cx}$ family of proteins, a number of short mimetic peptides were chemically synthesized and coupled to immunogenic carriers to generate antibodies to target specific domains and epitopes. The two highly conserved extracellular loops of $\mathrm{Cx}$ have proven to be poorly immunogenic, and it has been difficult to generate antibodies to these domains. Nevertheless, antibodies to both extracellular loop domains have been used in studies of a wide range of functions underwritten by $\mathrm{Cx}$ channels. These include (1) the topographical arrangement of $\mathrm{Cx}$ proteins in the membrane (Zimmer et al. 1987), (2) the roles of gap junctions in the development of mouse embryos (Becker et al. 1995), (3) $\mathrm{Ca}^{2+}$ wave signaling across cell layers connected by gap junctions (Boitano et al. 1998), (4) subcellular assembly of gap junctions (Rahman et al. 1993), (5) coordination of $\mathrm{Ca}^{2+}$ transients in beating cardiac myocytes (Verma et al. 2009b), (6) Cx43 as a candidate component of the immunological synapse (Mendoza-Naranjo et al. 2011), (7) the functional importance of the two exposed extracellular loops (Goodenough et al. 1988), (8) CxHc organization in polarized cells (Clair et al. 2008) and (9) tracking conformational changes as Cx traffic from the Golgi apparatus to gap junctions (Sosinsky et al. 2007). Antibodies to peptides from intracellular regions have been used extensively as diagnostic immunological/analytical tools and are widely available from commercial sources.

Although reagents such as heptanol, octanol, oleamide, lithium ions, quinine derivatives, carbenoxolone, fenamates, anandamide, oleamide, triarylmethanes and glycyrrhetinic acid inhibited gap junctional communication (Herve and Dhein 2010; Juszczak and Swiergiel 2009; Bodendiek and Raman 2010), there remained a need for more specific reagents with a known mechanism of action. From early on, it became evident that $\mathrm{Cx}$ mimetic peptides used to generate the antibodies to gap junctions might prove useful as chemical tools to manipulate channel operation; it was argued that the utility of antibodies was restricted by their size and limited penetration across the cell membrane and into intercellular regions where gap junctions are located. Such drawbacks would be overcome by using small mimetic peptides that could penetrate into intercellular junctions, disrupt the docking and/or operation of hemichannels and, thus, target the gap junction (Fig. 1).

Two studies using model systems marked the beginning of the exploration of $\mathrm{Cx}$ mimetic peptides as tools to study gap junction functions. The first took advantage of the contractile behavior displayed by embryonic chick heart myoballs and known to require coordination provided by intercellular communication via gap junctions. The effects of a series of $15 \mathrm{Cx}$ peptides, corresponding to short sequences mainly in intra- and extramembrane amino acid regions of the tetraspan membrane protein in delaying gap junction functions, were determined (Warner et al. 1995). A parallel study that used six dodecapeptide Cx mimetics to interrupt communication across gap junctions generated in Xenopus oocytes transfected with RNA to Cx32 (Dahl et al. 1994) likewise pointed to the potential of using short peptides to tamper with Cx-dependent intercellular communication. Warner et al. (1995) pinpointed motifs that included short sequence motifs, SRPTEK in extracellular loop 1 and SHVR in extracellular loop 2, as likely potent peptides for use in disrupting cell communication. These motifs were later incorporated into Gap26 and -27 mimetic peptides and their close homologues (see Tables 1, 2, 3). Kwak and Jongsma (1999) used dye coupling and dual patch-clamp approaches to study the inhibition of $\mathrm{Cx}$ channels using peptide mimetics from the second extracellular loop of $\mathrm{Cx} 43$ and $\mathrm{Cx} 40$. An extensive literature has 
Table 1 Examples of the use of Gap26 and -27 mimetic peptides in studying the functions of gap junctions and connexin hemichannels in tissues/organs, cell layers and slices

\begin{tabular}{|c|c|c|c|}
\hline Test model & Peptide & Effects & Reference \\
\hline Arteries & Gap26/27 & Block rhythmic contractions & Chaytor et al. (1997) \\
\hline Mesenteric arteries & Gap27 & Attenuates hyperpolarization & Dora et al. (1999) \\
\hline Endothelium & Gap27 & Attenuates Ach relaxations & Hutcheson et al. (1999) \\
\hline Arteries & Gap26/27 & Block EHF signaling & Chaytor et al. (2005) \\
\hline Kidney & Gap27 & Blocks renal vasodilatation & De Vriese et al. (2002) \\
\hline Heart tissue & Gap26 & Aids recovery after hypoxia & Hawat et al. (2010) \\
\hline Heart lateral ventricle & Gap $27^{\mathrm{a}}$ & Aids recovery after ischemia & Davidson et al. (2012) \\
\hline Arteries & Gap27 & Lowered intercell resistance & Matchkov et al. (2006) \\
\hline Lung capillaries & Gap26/27 & Inhibit $\mathrm{Ca}$ waves & Parthasarathi et al. (2006) \\
\hline Trophoblasts/fibroblasts & Gap26/27 & Block bilayer signaling and reduce DNA damage & Bhabra et al. (2009) \\
\hline Various cell barriers & Gap27 & Blocks signaling across barriers & Sood et al. (2011) \\
\hline $\begin{array}{l}\text { Brain endothelial and MDCK } \\
\text { epithelial cells }\end{array}$ & Gap27 & Inhibits $\mathrm{Ca}$ oscillations & De Bock et al. (2012) \\
\hline Leukocytes & Gap27 & Inhibits ATP release & Eltzschig et al. (2006) \\
\hline Hippocampus & Gap27 & Impairs learning, memory & Bissiere et al. (2011) \\
\hline Hippocampus slices & Gap27 & Inhibits epileptiform activity & Samoilova et al. (2008) \\
\hline Rat amygdala & Gap27 & Induces amnesia & Stehberg et al. (2012) \\
\hline Spinal cord & Gap $27^{\mathrm{a}}$ & Reduces swelling, reduces neuronal cell death & O'Carroll et al. (2008) \\
\hline Optic nerve & Gap27 & Attenuates CNS injury & Chew et al. (2010) \\
\hline Hippocampus & $\mathrm{Gap} 27^{\mathrm{a}}$ & Decreases cell death & Yoon et al. (2010) \\
\hline Lung & Gap26 & Reduces neutrophil transmigration & Sarieddine et al. (2009) \\
\hline Various cells & Gap26 & Blocks microtissue assembly & Bao et al. (2011) \\
\hline Skin model systems & Gap27 & Increased migration and proliferation & Pollok et al. (2011) \\
\hline
\end{tabular}

Gap26, VCYDKSFPISHVR; Gap27, SRPTEKTIFI

${ }^{\text {a }}$ Gap27 analogue. See Table 2 for sequence. A Gap27 acting on Cx40 channels (SRPTEKNVFIV) has been used on vascular tissues where this $\mathrm{Cx}$ is expressed

since built up around the study of Cx-dependent cell communication processes, especially with peptides mimicking sequences in $\mathrm{Cx} 43$ and, to a lesser extent, $\mathrm{Cx} 40$ and $\mathrm{Cx} 37$, which are widely expressed in the vascular system as well as with Cx32 (De Bock et al. 2011). Gap26 and -27 have emerged as mimetic peptide tools that have entered the literature in studies that explore the operation and function of $\mathrm{Cx}$ channels in several settings (Tables 1,2). As discussed below, the blockage of direct cell coupling across gap junctions (Evans and Boitano 2001) is now likely to be a secondary event that follows initial interaction of the peptides with CxHcs. Recent work is increasingly focused on the translational and therapeutic possibilities offered by the action of the mimetic peptides, especially in averting or reversing tissue damage in ischemia and inflammation.

\section{Gap Junctions and CxHes}

The view that $\mathrm{CxHcs}$ possess functions in their own right and are able to operate in different modes from gap junctions has now become generally accepted (Goodenough and
Paul 2003; Bennett et al. 2003; Evans et al. 2006). CxHcs were detected in Xenopus oocytes (Ebihara and Steiner 1993), a test bed to study gap junction expression and function and where the channels were observed to open in low-Ca media. Hc opening was also detected in vertebrate retinal dendrites (Malchow et al. 1993). These early studies appeared against the background view that CxHcs sustained in open configuration in membranes would lead to potentially catastrophic cellular outcomes by allowing transmembrane escape from cells of small intracellular signaling molecules, e.g., ATP and glutamate, and would result in a collapse or dissipation of ionic gradients. The possible importance of $\mathrm{CxHcs}$ operating under normal physiological situations in cells and tissues was critically evaluated (Spray et al. 2006). Collateral evidence for the functional reality of $\mathrm{CxHcs}$ began to appear later for roles in pathology with, e.g., the demonstration that leaky mutated CxHcs in the ear were linked to deafness (Stong et al. 2006; Scott and Kelsell 2011) and a mutation in the intracellular loop of Cx43 that decreased single-channel conductance and is linked to neurological disturbances in oculodentodigital dysplasia (Lai et al. 2006). Reconstituted Hcs were used to 
Table 2 Examples of use of Gap 26 and 27 mimetic peptides on various cells in culture

\begin{tabular}{|c|c|c|c|}
\hline Test model/cells & Peptide & Effect & References \\
\hline Skin fibroblasts, keratinocytes & Gap27 & Increases migration in diabetes & Wright et al. (2012a, b) \\
\hline HeLa Cx43 GFP & Gap26/27 & Inhibit dye transfer & Berman et al. (2002) \\
\hline Lymphocytes & Gap26/27 & Inhibit transendothelial migration & Oviedo-Orta et al. (2002) \\
\hline T/dendritic cells & Gap27 & Cell sensitization abrogated & Ring et al. (2010) \\
\hline Mesenteric smooth muscle & Gap27 & Attenuates hyperpolerization & Dora et al. (1999) \\
\hline Alveolar epithelial & Gap27 & Inhibits $\mathrm{Ca}$ signaling & Boitano and Evans (2000) \\
\hline Alveolar epithelial & Gap26/27 & Inhibit dye transfer & Isakson et al. (2003) \\
\hline Neonatal myocytes & Gap26 & Inhibits ATP release in ischemia & Clarke et al. (2009) \\
\hline $\mathrm{HeLa} /$ cardiac cells & Gap26/27 & Inhibit $\mathrm{Ca}$ uptake and $\mathrm{Ca}$ waves & Verma et al. (2009b) \\
\hline $\mathrm{CD}^{+}{ }^{+} \mathrm{T}$ lymphocytes & Gap27 & Inhibits T-cell proliferation & Oviedo-Orta et al. (2010) \\
\hline $\mathrm{B}$ and $\mathrm{T}$ lymphocytes & Gap26/27 & Decrease antibody production & Oviedo-Orta et al. (2010) \\
\hline Corneal & Gap26 & ATP release and $\mathrm{Ca}$ waves blocked & Gomes et al. (2005) \\
\hline Ganglia & Gap2 $7^{\mathrm{a}}$ & Limits retinal ganglion injury & Danesh-Meyer et al. (2012) \\
\hline Neural retinal & Gap26 & Limits ATP release and development & Pearson et al. (2005) \\
\hline Astrocytes & Gap27 & Abolished NMDA excitotoxicity & Froger et al. (2010) \\
\hline Astrocytes & Gap26 & Blocks glutamate release & Jiang et al. (2011) \\
\hline Astroglia & Gap26/27 & Block glutamate release & Orellana et al. (2011) \\
\hline Glioma & Gap26/27 & Delay apoptosis, cell death & Decrock et al. (2009a, b) \\
\hline Astroglia & Gap26 & Influences neural inflammation & Karpuk et al. (2011) \\
\hline Glia & Gap26/27 & Inhibit ATP release & De Vuyst et al. (2009) \\
\hline Astroglia & Gap26 & Inhibits ATP release and activation of $\mathrm{P} 2 \mathrm{Y}$ receptors & Orellana et al. (2012a) \\
\hline Astrocytes & Gap26/27 & Induce anhedonia, depression & Sun et al. (2012) \\
\hline Blood-brain barrier endothelium & Gap27 & Inhibits ATP release and permeability of endothelium & De Bock et al. (2011) \\
\hline AT11 & Gap27 & Inhibits $\mathrm{Ca}$ waves & Isakson et al. (2001) \\
\hline Endothelium & Gap26 & Inhibits ATP release & Robertson et al. (2010) \\
\hline Bladder cancer & Gap26/27 & Inhibit ATP release & De Vuyst et al. (2006) \\
\hline T lymphocytes & $1,848^{\mathrm{b}}$ & Blocks GJ docking & Mendoza-Naranjo et al. (2011) \\
\hline Cardiomyocytes & Gap26 & Blocks $\mathrm{CxHc}$ in cardiac hypoxia & Shintani-Ishida et al. (2007) \\
\hline Platelets & Gap27 & Blocks Cx 43/37 channels & Vaiyapuri et al. (2012) \\
\hline Bone marrow stem cells & Gap27 & Confirms $\mathrm{Cx}$ channels absent & Yang et al. (2009) \\
\hline
\end{tabular}

${ }^{\text {a }}$ VDCFLSRPTEKT peptide 5 derived from extracellular loop 2 of $\mathrm{CxHc} 43$

${ }^{b}$ Sequence of the Cx mimetic peptide not disclosed

investigate the influence of $\mathrm{Ca}$ and atomic force microscopy, to study Hc pore opening (Thimm et al. 2005). It is now generally accepted that $\mathrm{CxHcs}$ open under environmental circumstances considered to be stressful to cells such as volume or osmotic changes; oxidative, metabolic and mechanical stresses; and especially hypoxia/ischemia.

If not contained, leaky CxHcs can lead to apoptosis and cell death (Saez et al. 2010; Decrock et al. 2009a, b). Binding of mimetic peptides such as extracellular loop peptides Gap26 and -27 to the extracellular face inhibited functions associated with $\mathrm{CxHcs}$; these are also regulated by membrane depolarization, phosphorylation of several sites on the carboxyl tail of Cx43 (Solan and Lampe 2009), S-nitrosylation (Retamal et al. 2006) and SUMOylation of lysine residues in the intracellular loop (Kjenseth et al. 2012). The particle-receptor hypothesis (see below) explained the mechanics of gating in those Cxs with extended cytoplasmic tails such as Cx43, Cx40 and Cx45 (Delmar et al. 2004). Recent evidence suggests that mimetic peptide perturbation of intracellular domains, especially the interactive cytoplasmic loop (CL) and the carboxyl tail (CT), also influences Hc functions (Ponsaerts et al. 2010). CxHc gating is also conditioned by signaling cascades operating in subplasmalemmal environs (Fig. 2).

Besides structural differences, with Hcs being asymmetrical and gap junctions being symmetrical double channels, there are other important differences between the functions of these weakly selective channels. CxHcs stand out in being responsive to environmental changes and contingencies. Gap junction channels allow the cytoplasms of cells to be linked directly, whereas open $\mathrm{CxHcs}$ provide channels connecting the cell's external environment with 
Table 3 Effects of various intracellular Cx mimetic and other short and mainly Cx43 peptides on gap junctions and hemichannels

\begin{tabular}{|c|c|c|c|}
\hline Test model & Peptide & Effect & Reference \\
\hline Brain synapses & Carboxyl tail & Prevents Cx36/GJ formation & Flores et al. (2012) \\
\hline Bladder cancer & Gap2 $4^{\mathrm{a}}$ & Inhibits ATP release & De Vuyst et al. (2006) \\
\hline Mouse hearts & Carboxyl tail ${ }^{\mathrm{b}}$ & $\begin{array}{l}\text { Increases } \mathrm{Cx} 43 \text { and ps368 } \\
\text { phosphorylation } \\
\text { and induces arrhythmia }\end{array}$ & O'Quinn et al. (2011) \\
\hline Heart & Carboxyl tail & May open gap junctions & Lewandowski et al. (2008) \\
\hline Heart & $\mathrm{R}$, any amino acid & May open gap junctions & Verma et al. (2009b) \\
\hline Cardiac mitochondria & Gap27 & Inhibits $\mathrm{Cx} 43$ & Rottlaender et al. (2012) \\
\hline T lymphocytes & Gap20 ${ }^{c}$ & Ineffective on gap junctions & Mendoza-Naranjo et al. (2011) \\
\hline Endothelium- denuded arteries & Gap20 ${ }^{c}$ & Ineffective on gap junctions & Chaytor et al. (1997) \\
\hline C6 glioma cells & L2 segment nonapeptide & Blocks $\mathrm{CxHc}$ but not gap junctions & Wang et al. (unpublished) \\
\hline $\begin{array}{l}\text { Corneal endothelial and C6 glioma } \\
\text { cells }\end{array}$ & TAT-L2 & Blocks $\mathrm{CxHc}$ but not gap junctions & Ponsaerts et al. (2010) \\
\hline Basolateral amygdala & Cx43-L2 TAT & Blocks gliotransmitter release & Stehberg et al. (2012) \\
\hline MDCK & $\begin{array}{l}\text { CT9 peptide }{ }^{\mathrm{b}} \text { Carboxyl } \\
\text { tail }\end{array}$ & $\begin{array}{l}\text { Blocks Ca oscillations by removing } \\
\text { high Ca closure }\end{array}$ & De Bock et al. (2012) \\
\hline
\end{tabular}

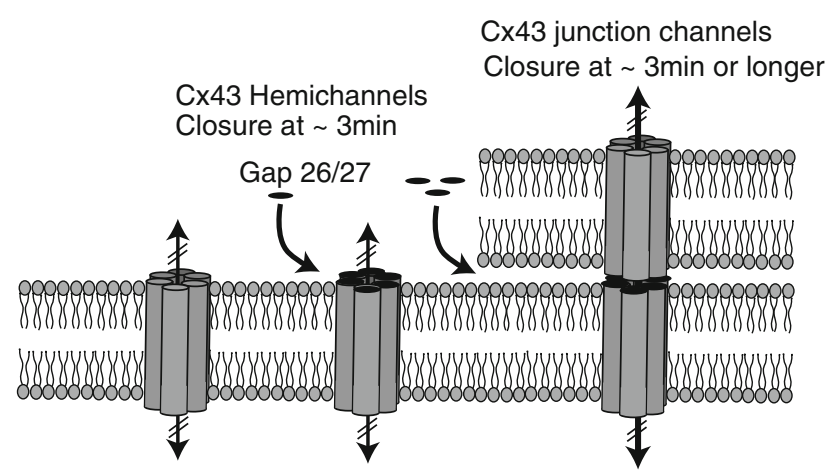

Fig. 1 Mechanism of action of Gap26 and -27 mimetic peptides. Peptides bind to extracellular loop regions one and two, respectively, of $\mathrm{CxHc}$, causing closure of channels within minutes. At later time intervals (30 min or longer) and depending on factors such as cell confluency, tissue, organ, tissue slice origin and thickness and conditions of perfusion of various organs, peptides permeate into intercellular spaces in gap junctions, causing disruption and diminished cell coupling. CxHcs with attached peptide move laterally toward the rims of gap junction plaques as they assemble and are then internalized

the cytoplasmic mileu beneath the plasma membrane. In a cell-signaling context, changes in $\mathrm{CxHc}$ open probability provide a mechanism for paracrine intercellular communication by allowing small molecules such as ATP and K to exit and $\mathrm{Ca}$ to enter cells. ATP release underwrites purinergic intercellular signaling (Isakson et al. 2001; Paemeleire et al. 2000; Kang et al. 2008), a function shared with pannexin channels.
Gap junction channels exist normally in open mode, and an elevation in intracellular $\mathrm{Ca}^{2+}$ leads to closure (generally 500-2,000 nM). In contrast, CxHcs open at $500 \mathrm{nM}$ (De Vuyst et al. 2006, 2009, 2011). Differences in Ca sensitivity of the two channel types may relate to their complementary roles in regulating intracellular $\mathrm{Ca}$ oscillations and the intercellular propagation of $\mathrm{Ca}$ waves (Verma et al. 2009a; Orellana et al. 2012b; De Bock et al. 2012). The various intracellular processes that influence the gating of $\mathrm{Cx} 43 \mathrm{Hcs}$ are shown in Fig. 2b. Gap junctions and CxHcs respond differently to lipopolysaccharide and basic fibroblast growth factor, a consequence of their involvement in releasing ATP (De Vuyst et al. 2007); their channel functions also respond differently to many growth factors (Schalper et al. 2012).

\section{Widespread Use of Gap26 and Gap27 Mimetic Peptides}

Cx43 is by far the most widely distributed $\mathrm{Cx}$ in tissues and organs. It is therefore not surprising that Gap26 and -27, derived from $\mathrm{Cx} 43$ sequences, have found extensive use. A modified Gap27 peptide (Table 1) incorporating a sequence mimicking that in $\mathrm{Cx} 40$ has also proven useful in vascular tissues and other tissues where both Cxs are present (Chaytor et al. 1999; Wright et al. 2009). Early studies showed that inhibition by mimetic peptides was largely reversible as assessed by intercellular transfer of small fluorescent "reporter" dyes of varying size and by 

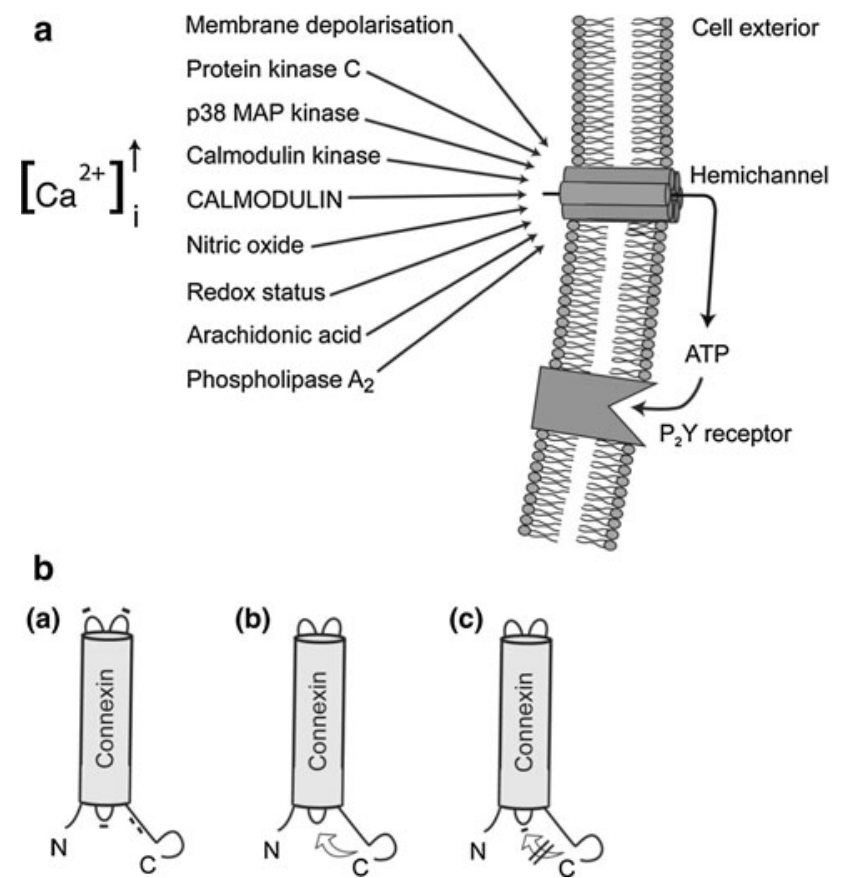

Fig. 2 a Several intracellular signals and events influence $\mathrm{CxHc}$ functions. Membrane depolarization above $+30 \mathrm{~V}$ opens Hc. Several kinases may also be involved; PKC closes Hc, while p38MAPK and calmodulin kinases result in $\mathrm{Hc}$ opening. The cytoplasmic $\mathrm{Ca}$ concentration $\left(\left[\mathrm{Ca}^{2+}\right]_{\mathrm{i}}\right)$ is also an important modulator; below $500 \mathrm{nM}\left[\mathrm{Ca}^{+}\right]$calmodulin is a key $\mathrm{Ca}$ binding protein and specific binding sites are present on $\mathrm{Cx}$. An increase in intracellular $\mathrm{Ca}$ causes Hc opening, while Hc activation is lost at higher concentrations. Arachidonic acid stimulates $\mathrm{Hc}$ opening, and amino acid metabolites generated by $\mathrm{PLA}_{2}$ activation may contribute to this. Nitric oxide and oxidative stress also result in opening of Hc. Figure modified from De Vuyst et al. (2009). b $a$ Sites on the exposed extramembrane regions of $\mathrm{Cx} 43$ where the mimetic peptide sequences originated. $b$ Proposed intramolecular mechanism of $\mathrm{CxHc}$ gating involving interaction of the carboxyl tail with the intracellular loop. $c$ Binding of a nonapeptide mimetic derived from L2, the Cx43 intracellular loop region to a site on the carboxyl terminus regulates the closure of $\mathrm{CxHc}$ and leads to blockage of the channel

measuring the extent of $\mathrm{Ca}$ wave propagation over multiple rows of cells (Boitano and Evans 2000).

As the operational presence of CxHcs became evident, inhibition by mimetic peptides of ATP release in a wide range of tissues and cells (Tables 1,2), of glutamate in astrocytes (Yang et al. 2009) and astrocytes/microglia (Orellana et al. 2011) and of ion trafficking, especially $\mathrm{Ca}^{2+}$ entry, were observed. Uptake of reporter dyes across CxHcs became a reliable and routine method to demonstrate open or leaky CxHcs (Li et al. 1996). A range of other effects were also noted on prolonged exposure (20 min or longer) to the mimetic peptides such as smooth muscle contraction in endothelium-denuded arteries (Chaytor et al. 1997; Hutcheson et al. 1999) and immunoglobulin production by lymphocytes (Oviedo-Orta et al. 2001). Subsequently, as the presence of $\mathrm{CxHcs}$ widened, it became increasingly clear that the primary action of Gap26 and -27 is in fact directed at CxHcs. Nevertheless, a combination of direct signaling across gap junctions and paracrine signaling acting through metabotropic purinergic receptors following release of ATP (Fig. 2) provides scope for complementary intercellular interplay involving both routes in several settings (Anselmi et al. 2008; Cotrina et al. 1998).

Initial experiments showing inhibition by mimetic peptides of CxHcs were carried out mainly using cultured cells (Table 2), followed by numerous examples in various tissues and organs, cell layers and thin tissue slices (Table 1). The growing attribution of nonjunctional properties to CxHcs (Cotrina et al. 2008; Kameritsch et al. 2011) has led to studies that attempt to unravel the potential functions in the realms of adhesion and cell movement. Enhancement of migration of dermal fibroblasts after treatment with Gap27 pointed to nonjunctional roles for $\mathrm{CxHcs}$ in cell movement and extending, e.g., to assessing their potential translational application in addressing their efficacy in accelerating wound healing in diabetes and in a range of micro-/macrovascular diseases (Wright et al. 2009, 2012a; Pollok et al. 2011). Gap27 increased migration of human keratinocytes and dermal fibroblasts, and the efficacy of the mimetic peptide was different in euglycemia and hyperglycemia (Wright et al. 2012b). Gene array approaches indicated that Gap27 induced upregulation of genes involved in extracellular matrix remodeling and cell adhesion. Exposure of cells to Gap27 may have effects on Cx43 phosphorylation, especially of serine 368 ; phosphorylation of this amino acid decreases $\mathrm{Cx} 43$ channel activity (Solan and Lampe 2009) and is a key process in the gating of Cx43 channels. Many of the effects of the mimetic peptides were seen after long-term exposures. Cx43 has been detected in the inner mitochondrial membrane of heart cells and has been implicated in cardiac preconditioning (Boengler et al. 2009; Rottlaender et al. 2012). The opening of mitochondrial $\mathrm{CxHc}$ influences $\mathrm{K}^{+}$ fluxes in processes that are linked to cardioprotection. The functions of $\mathrm{Cx} 43 \mathrm{Hc}$ at this location are open to study using mimetic peptides developed to $\mathrm{Cx} 43$ cytoplasmic sequences (Verma et al. 2009a).

\section{Mechanism of Action of $\mathrm{Cx}$ Mimetics}

To further develop and refine the actions of Cx mimetics, it is important to gain insight into the mechanisms by which they block Cx channels. A major advance was the demonstration that the primary action of Gap26 and -27 was likely to be on $\mathrm{CxHcs}$ prior to blockage of gap junctions. With the acceptance that $\mathrm{CxHcs}$ and gap junctions were targets but in different time frames, the effects of the peptides on both were examined using electrophysiological approaches. These had already proven useful in studying 
electrical coupling across gap junctions in cell pairs and the electrical properties of CxHcs (Harris 2001; Contreras et al. 2003; Saez et al. 2005). Using a voltage-clamp approach in nonconfluent and confluent HeLa cells expressing Cx43, Gap26 inhibited macroscopic currents through CxHcs in 2-3 min. In contrast, electrical coupling in cell pairs was delayed and completely inhibited after $30 \mathrm{~min}$ or more (Desplantez et al. 2012), indicating direct action of Gap26 on an exposed extracellular loop, as previously suggested by studies of CxHcs inserted into lipid bilayers (Liu et al. 2006). The extended time course of action on gap junctional electrical coupling suggests that longer diffusion pathways into plasma membrane junctional domains lead ultimately to blockage of gap junctional coupling (Fig. 1). The changes in conductance and voltage gating of CxHcs by Gap26 suggested interaction of the peptide at a consensus sequence in the first extracellular loop that may contribute to the inner wall of the pore (Sosinsky and Nicholson 2005), resulting in a decrease in channel diameter in the extracellular vestibule. Desplantez et al. (2012) also proposed that, of the two voltage gates controlling $\mathrm{Hc}$, the slow gate is the more likely to be influenced by the binding of Gap26.

An expanded complementary study by Wang et al. (unpublished) examined the mechanism of action of Gap26 and -27 in HeLa cells stably transfected with $\mathrm{Cx} 43$ and in pig ventricular myocytes endogenously expressing Cx43 using a voltage-clamp approach. Both mimetic peptides inhibited $\mathrm{Cx} 43 \mathrm{Hc}$ unitary currents within minutes. An important outcome of this study with cardiac translational implications was that unitary current activity was promoted by a moderate elevation of cytoplasmic $\mathrm{Ca}$, an event observed in cardiac arrhythmogenesis.

Gap26 and -27 have been used mainly to inhibit $\mathrm{Cx} 43$ channels, but actions on other $\mathrm{Cx}$ channels have also been studied. For example, Wright et al. (2009) carried out an extensive study of the effects of Gap26 and -27 on dye coupling in cells expressing several human Cxs and found that Gap27 had broader Cx specificity than Gap26. In some situations where multiple Cxs are expressed, as in skin, broad specificity can be an advantage.

The precise protein domains to which Gap26 and -27 mimetic peptides attach and any conformational changes induced in $\mathrm{Cx}$ channels remain to be determined. Fluorescently labeled Gap26 and -27 are poorly soluble; but evidence points to attachment and retention at cell exteriors, and problems of image resolution could not answer the issue of whether attachment of a mimetic peptide ligand to a "channel receptor" sequence can lead to peptide internalization (Evans, unpublished work). Voltage-clamp approaches have been useful in deciphering the inhibitory action of these peptides on $\mathrm{Cx}$ channels and go a long way toward resolving questions concerning the specificity of mimetic peptide inhibitory effects. Cx mimetics have been claimed as effective inhibitors due to steric pore block (Wang et al. 2007). Steric block may indeed occur, but recent data indicate that it only occurs when peptides are used in the range of $1 \mathrm{mM}$ and above (Wang et al. unpublished). The examples shown in Tables 1 and 2 used mainly protein concentrations of $100-250 \mu \mathrm{M}$. In the vast majority of these studies, investigators have used scrambled peptides or short peptides derived from regions believed not to be directly involved in channel operation (often internal sequences) as controls and, in each instance, they pointed to a high sequence dependence of mimetic peptide action in blocking gap junctional coupling and, more recently, ATP release or dye entry across CxHcs.

Pannexins, of which three are identified compared to around 22 in the $\mathrm{Cx}$ family of proteins, also form oligomeric channels with a similar tetraspan topographical arrangement in the membrane to CxHcs. However, these two protein families share no amino acid homology. Pannexins, unlike Cxs, are posttranslationally glycosylated (D'Hondt et al. 2009; Scemes et al. 2009) and are disinclined to dock with partner pannexins on neighboring cells. It follows that they are not expected to generate gap junction-like structures and, indeed, are found at higher levels inside cells (D'Hondt et al. 2011). In contrast, a recent report claims that they can form gap junctions and act as Ca leak channels in the endoplasmic reticulum (Ishikawa et al. 2011). Pannexins are relatively unaffected by changes in cytoplasmic $\mathrm{Ca}^{2+}$ levels and, unlike $\mathrm{Cx}$, are calmodulin-insensitive. Pannexins are especially abundant in neural tissues. The action of Gap26 and -27 on pannexin channel currents has not yet been rigorously tested. It is worth noting that high sequence diversity occurs in the intracellular loop of Cx proteins; the carboxyl tail of larger $\mathrm{Cx}$ proteins also varies in length, sequence and the extent of posttranslational modification.

Small peptides generally have little structural organization but may assume some on binding to a target that then becomes subject to conformational change. Studies of the interaction of calmodulin with mimetic peptides from the intracellular loop of $\mathrm{Cx} 43$ demonstrate a way forward toward functionally dissecting this key region of $\mathrm{Cxs}$ (Myllykoski et al. 2009). A calmodulin binding region in Cx43 was located to amino acid residues 136-158 (Zhou et al. 2007). Clearly, further knowledge of the structural organization of $\mathrm{Cx} 43 \mathrm{Hc}$ is awaited along the lines available on CxHc26 (Maeda et al. 2009; Oshima et al. 2011).

Table 3 lists the growing number of mimetic peptides derived from the $\mathrm{CL}$ and $\mathrm{CT}$ that act on $\mathrm{CxHcs}$ and gap junctions. Many of these peptides are not able to cross the plasma membrane. To gain access to their sites of action, many of these mimetics need to be attached first to "Trojan" cell-penetrating peptides that contain a 
membrane-translocation motif (Jarver and Langel 2006). Intracellular loop mimetic peptides with a positive charge due to several lysine residues stand out as candidates, for they can, depending on length, gain access to intracellular targets without need for attachment of a membrane-penetrating peptide or by microinjection, as discussed below. Indeed, peptides of around $1 \mathrm{kDa}$ or less may be able to access the cytoplasm via open CxHcs.

\section{Mimetics and Other Cx Peptides as Agents to Address Pathology}

In a cardiac context, blockage by Gap26 and -27 of gap junctional coupling between myocytes negated their candidacy for use, especially in therapeutic approaches to address cardiac arrhythmia, for the outcomes of peptide treatment were likely to compound the pathology. Consequently, studies in heart focused on nonmimetic hexapeptides shown to be prorhythmic, especially ZP123 derived from AAp10 and later renamed rotigaptide (Hagen et al. 2009; Herve and Dhein 2010). This hexapeptide promoted changes to $\mathrm{Cx}$ phosphorylation, increased gap junctional coupling (Clarke et al. 2006) and showed promise in animal models, where it prevented ventricular tachycardia in myocardial ischemia (Xing et al. 2003). However, following inconclusive clinical trials, rotigaptide was not developed further. Cellular studies showed that despite its prorhythmic action on gap junctions, ZP123 also led to the opening of CxHcs, causing ATP release. In a cardiac myocyte ischemia model, Gap26 blocked the release of ATP, whereas ZP123 enhanced its release across $\mathrm{Cx} 43 \mathrm{Hc}$ (Clarke et al. 2009). Other antiarrhythmic peptides—such as Gap134, a prorhythmic dipeptide-were also developed (Hennan et al. 2009).

In the meantime, encouraging outcomes in addressing ischemic cardiomyopathy using Gap26 have appeared. These results can be explained by the direct action of this mimetic peptide on $\mathrm{CxHc}$ rendered open under hypoxic/ ischemic conditions. Hawat et al. (2010) showed that following myocardial ischemic insult, Gap26 helped to confer protection through its binding to and blockage of $\mathrm{Cx} 43 \mathrm{Hc}$. Similar protection from hypoxic stress by these peptides has also been reported. Vascular leak and retinal ganglion cell death were reduced by application of a close homologue of Gap27 in an atrial ischemia model where $\mathrm{Cx} 43 \mathrm{Hc}$ expression was increased (Danesh-Meyer et al. 2012). The same group also reported that infusion of Gap27 in a large animal model with cerebral injury delayed the onset of ischemic injury and suggested that Gap27 homologue peptides reduced inflammation. For example, mimetic peptide treatment reduced the spread of damage after traumatic spinal cord injury where $\mathrm{Cx} 43 \mathrm{Hc}$ plays a critical role (O'Carroll et al. 2008; Huang et al. 2012). Such studies combine to show that Gap26 and -27 mimetic peptides acting on CxHc-related functions, especially in situations of tissue injury, show therapeutic potential. In brain, inhibition of inflammation-induced activation of $\mathrm{Cx} 43 \mathrm{Hc}$ in astroglial cells was attenuated by treatment with Gap26 and -27 , suggesting that the channels play a critical role in instigating neuronal death and pointing to a neuroprotective role for these mimetic peptides (Froger et al. 2010). Interaction of the mimetic peptides with $\mathrm{CxHcs}$ is also likely to modify intracellular signaling cascades in subplasma membrane environments (Fig. 2a).

The action of Gap26 and -27 on CxHcs and later at gap junctions encouraged the view that pathological outcomes could be fine-tuned if mimetic peptides were to become available that confined their blocking action on CxHcs resident in the plasma membrane. Attention had already focused on the intracellular loop region implicated in explaining gap junction gating in cardiac cells and involving intramolecular interaction of the carboxyl tail region with the intracellular loop L2 region (a region in Cx43 incorporating amino acids 119-144) and described as the particle-receptor hypothesis (Delmar et al. 2004). The role of the L2 domain as a key molecular determinant of Cx43 function originated from the acidification-related closure of gap junctions (Delmar et al. 2004), and the particle-receptor hypothesis has been proposed to explain $\mathrm{CX} 43$ closure during acidification, with the $\mathrm{CT}$ moving as a flexible gating particle that binds to the L2 site at the intracellular vestibule and leading to closure of the gap junction pore. Because of the similarity to the inactivation of $\mathrm{K}^{+}$channels, this mechanism has also been called the ball and chain model of gap junction closure. A 34-amino acid nonmimetic peptide (RXP-E) and its derivatives were developed to target the Cx43CT (Shibayama et al. 2006; Lewandowski et al. 2008; Verma et al. 2009a). When coupled to cell-penetrating peptides, these composite peptides successfully restored gap junctional coupling and impulse propagation in cultured neonatal rat ventricular cardiomyocytes. Although the ability of L2 peptide to bind to the $\mathrm{Cx} 43 \mathrm{CT}$ region has been intensively studied, less is known about how it is influenced by $\mathrm{pH}$.

Loop-tail interactions also control $\mathrm{Cx} 43 \mathrm{Hc}$ opening (Ponsaerts et al. 2010). The interaction of a cytoplasmic loop domain with the C-terminal region is an important requisite for the opening of $\mathrm{Cx} 43 \mathrm{Hc}$ in response to stimuli such as lowering of extracellular $\mathrm{Ca}^{2+}$ or increasing intracellular $\mathrm{Ca}^{2+}$. In contrast, $\mathrm{Cx} 43$ gap junctions behave in the opposite manner and are closed by intramolecular loop-tail interactions (Delmar et al. 2004; Hirst-Jensen et al. 2007). Interfering with loop-tail interactions can inhibit the operation of $\mathrm{Cx} 43 \mathrm{Hc}$. One way to suppress $\mathrm{CxHc}$ operation in response to high intracellular $\mathrm{Ca}^{2+}$ is to 
activate the actomyosin contractile system, a process that appears to physically dislodge the CT from the CL region (Ponsaerts et al. 2012). Importantly, the selective myosin11-ATPase inhibitor blebbistatin restores $\mathrm{Cx} 43 \mathrm{Hc}$ activity when cells are exposed to high intracellular $\mathrm{Ca}$ (Ponsaerts et al. 2012). The proteins involved in this mechanism linking $\mathrm{Cx} 43 \mathrm{Hc}$ and the actomyosin contractile system have not been identified, but a likely target is the $\mathrm{CT}$ region of $\mathrm{Cx} 43 \mathrm{Hc}$, for $\mathrm{Cx} 43$ lacking the $\mathrm{CT}$ is inactive. Even in the absence of a functional actomyosin cytoskeleton, loop-tail interactions in $\mathrm{Cx} 43 \mathrm{Hc}$ can be disrupted using mimetic peptides from the L2 region, and coupling the peptides to a TAT cell-penetrating sequence inhibits $\mathrm{CxHc}$ opening. An important interactive target of L2region peptides is the last 10 amino acids of the carboxyl tail (CT10). Direct binding between the L2 domain and CT10 has been demonstrated by surface plasmon resonance. Thus, TAT-L2 allows exploitation of the opposite regulation of gap junctions and $\mathrm{Cx} 43 \mathrm{Hc}$ and can provide a route to selectively inhibit $\mathrm{Cx} 43 \mathrm{Hc}$ while maintaining gap junctional communication. The importance of the 10amino acid terminal carboxyl domain has been studied in detail also using electrophysiological approaches in Xenopus oocytes where the TAT-L2 and TAT-CT10 peptide constructs have been crucial in analyzing and deciphering intramolecular loop-tail interactions (Ponsaerts et al. 2010, 2012). These studies illustrate how mimetic peptide approaches for selectively studying the physiological functions of $\mathrm{Cx} 43 \mathrm{Hc}$ can complement knockdown/knockout approaches in, e.g., processes leading to cell death (Decrock et al. 2011) and in brain functions in the basolateral amygdala, where $\mathrm{Cx}$ mimetic peptides such as Gap27 demonstrate that $\mathrm{Cx} 43 \mathrm{Hc}$ activities are implicated in amnesia (Stehberg et al. 2012).

A short nonmimetic peptide (designated RXP-E) that bound to the carboxyl tail of Cx43, derived from heart lysates and studied in animal and cellular models, prevented action potential block in the heart (Lewandowski et al. 2008). A series of nonmimetic peptides with a motif designated RXP and containing a predominance of basic amino acid increased the mean open time of gap junction channels; these peptides were proposed as potential functional regulators in ischemia-induced arrhythmias (Shibayama et al. 2006; Verma et al. 2009a).

Currently, the application of novel short peptides mimicking sequences in the L2 region of Cx43 (Delmar et al. 2004) where a putative calmodulin binding site is identified (Zhou et al. 2007) proceeds. One major aim is to design mimetic peptides that confine their blocking actions to $\mathrm{CxHcs}$ with no interference on gap junction functionality, thus avoiding pro-arrhythmic consequences and allowing the bound mimetic peptide to arrest, e.g., the loss of vital cell metabolites via CxHcs in cardiomyocytes subject to hypoxia or ischemia perfusion injury. A potential tool for more selective inhibition of Hcs without associated inhibition of gap junctions is a synthetic mimetic peptide corresponding to the $\mathrm{L} 2$ region that, when delivered into the cell by a whole-cell recording pipette, prevented gap junctional opening to the subconductance state at high transjunctional voltage and increased the channel open time (Ponsaerts et al. 2010). Also, L2 peptide linked to the TAT membrane translocation motif (TAT-L2) inhibited $\mathrm{Cx} 43 \mathrm{Hc}$ activation, further suggesting that prevention of interaction of CT and CT suppresses Hc opening. Consequently, the particle-receptor hypothesis described above has an opposite outcome for Hcs compared to gap junctions. This raises questions concerning why this is so, for the composite proteins of the channels are identical but the $\mathrm{Ca}$ sensitivity of the $\mathrm{Cx} 43 \mathrm{Hc}$ and gap junctions differs. It now appears that intracellular interactive partners may also be different at the cytoplasmic aspects of junctional and nonjunctional regions of the plasma membrane. One possible reason for these differences is that Hcs interact with the actomyosin contractile system, causing dynamic looptail interactions that control Hcs that differ from those occurring at gap junctions (Ponsaerts et al. 2012).

New mimetic peptides derived from the carboxyl tail of $\mathrm{Cx} 43$ are also being assessed. Here, peptide mimetic design has to deal with a region where the CT interacts with cytoskeletal elements (Herve et al. 2011; Palatinus et al. 2011). This region also incorporates several phosphorylation sites that condition channel gating (Solan and Lampe 2009). In the heart, the cytoskeletal adaptor protein ankyrin-G interacts with $\mathrm{Cx} 43$ and is a likely key intercalated disc complex in the pathophysiology of arrhythmias (Sato et al. 2011). A short Cx43-CT peptide incorporating the last nine amino acids and linked to a cell permeabilization sequence inhibited pathological changes at gap junctions that are related to ventricular arrhythmias (O'Quinn et al. 2011). This peptide disrupted the interaction between the PDZ domain of ZO1 and Cx43, thus accelerating assembly of gap junctions from a precursor pool of Hcs (Hunter et al. 2005; Rhett and Gourdie 2012). The peptide also enhanced PKC-epsilon-associated phosphorylation at the Cx43-S368 site, an effect that is activated in ischemic preconditioning and can reduce cardiac injury (Ek-Vitorin and Burt 2012; Srisakuldee et al. 2009). A similar peptide with the same sequence named CT9 prevented high $\mathrm{Ca}-$ induced closure of $\mathrm{Cx} 43 \mathrm{Hc}$ (De Bock et al. 2012; Ponsaerts et al. 2012). In the same vein, a 15-amino acid mimetic peptide derived from a sequence in the CT of $\mathrm{Cx} 36$ modified gap junction conductance in goldfish electrical synapses, and this peptide was injected intradendritically (Flores et al. 2012). 


\section{Concluding Comments}

Peptides that mimic short sequences in extramembrane domains of $\mathrm{Cx}$ proteins show huge potential in addressing Cx-based communicationopathies by pharmacological means. The functions attributed to $\mathrm{Cx}$, especially $\mathrm{Cx} 43$, continue to expand and include not only roles in intercellular cell communication effected by $\mathrm{CxHc}$ and gap junctions but also cell adhesion, cell migration and mitochondrial inner membrane channel functions. It is likely that the range of $\mathrm{Cx}$ mimetics and their applications will increase, for they provide activation mechanisms for manipulation of intercellular signaling and communication. Furthermore, the peptides can also help cells protect themselves from events emanating from leaky channels, events that may ultimately lead to apoptosis. Intriguingly, in the brain the Gap26 and -27 mimetic peptides that act mainly on astrocyte $\mathrm{Cx}$ channels have been shown to affect depression (anhedonia), epileptiform activity, memory consolidation and amnesia, further emphasizing the importance of $\mathrm{Cx}$-mediated communication and signaling in a wide range of settings.

Acknowledgements We thank Nan Wang for critically reading and commenting on the manuscript. Funding for L. L. was from the Fund for Scientific Research, Flanders (G.0140.08, 3G0134.09, G.0298.11N and 3G.057112N), and Belgian Science Policy projects P6/31 and P7. G. B. was supported by the Fund for Scientific Research, Flanders (G.0298.11N) and Belgian Science Policy projects P6/28 and P7. W. H. E. received support from the British Heart Foundation (PG/01/1298 and PG/05/051).

Open Access This article is distributed under the terms of the Creative Commons Attribution License which permits any use, distribution, and reproduction in any medium, provided the original author(s) and the source are credited.

\section{References}

Anselmi F, Hernandez VH et al (2008) ATP release through connexin hemichannels and gap junction transfer of second messengers propagate $\mathrm{Ca}^{2+}$ signals across the inner ear. Proc Natl Acad Sci USA 105(48):18770-18775

Bao B, Jiang J et al (2011) Connexon-mediated cell adhesion drives microtissue self-assembly. FASEB J 25(1):255-264

Becker DL, Evans WH et al (1995) Functional analysis of amino acid sequences in connexin43 involved in intercellular communication through gap junctions. J Cell Sci 108(Pt 4):1455-1467

Bennett MV, Contreras JE et al (2003) New roles for astrocytes: gap junction hemichannels have something to communicate. Trends Neurosci 26(11):610-617

Berman RS, Martin PE et al (2002) Relative contributions of NO and gap junctional communication to endothelium-dependent relaxations of rabbit resistance arteries vary with vessel size. Microvasc Res 63(1):115-128

Bhabra G, Sood A et al (2009) Nanoparticles can cause DNA damage across a cellular barrier. Nature Nanotechnol 4(12):876-883

Bissiere S, Zelikowsky M et al (2011) Electrical synapses control hippocampal contributions to fear learning and memory. Science 331(6013):87-91
Bodendiek SB, Raman G (2010) Connexin modulators and their potential targets under the magnifying glass. Curr Med Chem 17(34):4191-4230

Boengler K, Stahlhofen S et al (2009) Presence of connexin43 in subsarcolemmal, but not in interfibrillar cardiomyocyte mitochondria. Basic Res Cardiol 104(2):141-147

Boitano S, Evans WH (2000) Connexin mimetic peptides reversibly inhibit $\mathrm{Ca}^{2+}$ signaling through gap junctions in airway cells. Am J Physiol Lung Cell Mol Physiol 279(4):L623-L630

Boitano S, Dirksen ER et al (1998) Sequence-specific antibodies to connexins block intercellular calcium signaling through gap junctions. Cell Calcium 23(1):1-9

Chaytor AT, Evans WH et al (1997) Peptides homologous to extracellular loop motifs of connexin 43 reversibly abolish rhythmic contractile activity in rabbit arteries. J Physiol 503(Pt 1): 99-110

Chaytor AT, Martin PE et al (1999) The endothelial component of cannabinoid-induced relaxation in rabbit mesenteric artery depends on gap junctional communication. J Physiol 520(Pt 2): $539-550$

Chaytor AT, Bakker LM et al (2005) Connexin-mimetic peptides dissociate electrotonic EDHF-type signalling via myoendothelial and smooth muscle gap junctions in the rabbit iliac artery. Br J Pharmacol 144(1):108-114

Chew SS, Johnson CS et al (2010) Role of connexin43 in central nervous system injury. Exp Neurol 225(2):250-261

Clair C, Combettes L et al (2008) Extracellular-loop peptide antibodies reveal a predominant hemichannel organization of connexins in polarized intestinal cells. Exp Cell Res 314(6): $1250-1265$

Clarke TC, Thomas D et al (2006) The antiarrhythmic peptide rotigaptide (ZP123) increases gap junction intercellular communication in cardiac myocytes and HeLa cells expressing connexin43. Br J Pharmacol 147(5):486-495

Clarke TC, Williams OJ et al (2009) ATP release by cardiac myocytes in a simulated ischaemia model: inhibition by a connexin mimetic and enhancement by an antiarrhythmic peptide. Eur J Pharmacol 605(1-3):9-14

Contreras JE, Saez JC et al (2003) Gating and regulation of connexin43 (Cx43) hemichannels. Proc Natl Acad Sci USA 100(20):11388-11393

Cotrina ML, Lin JH et al (1998) Connexins regulate calcium signaling by controlling ATP release. Proc Natl Acad Sci USA 95(26): $1574-15735$

Cotrina ML, Lin JH et al (2008) Adhesive properties of connexin hemichannels. Glia 56(16):1791-1798

Dahl G, Nonner W et al (1994) Attempts to define functional domains of gap junction proteins with synthetic peptides. Biophys J 67(5): 1816-1822

Danesh-Meyer HV, Kerr NM et al (2012) Connexin43 mimetic peptide reduces vascular leak and retinal ganglion cell death following retinal ischaemia. Brain 135(Pt 2):506-520

Davidson JO, Green CR et al (2012) Connexin hemichannel blockade improves outcomes in a model of fetal ischemia. Ann Neurol 71(1):121-132

De Bock M, Culot M et al (2011) Connexin channels provide a target to manipulate brain endothelial calcium dynamics and bloodbrain barrier permeability. J Cereb Blood Flow Metab 31(9): 1942-1957

De Bock M, Wang N et al (2012) Connexin-43 hemichannels contribute to cytoplasmic $\mathrm{Ca}^{2+}$ oscillations by providing a bimodal $\mathrm{Ca}^{2+}$-dependent $\mathrm{Ca}^{2+}$ entry pathway. J Biol Chem 287 (15):12250-12266

De Vriese AS, Van de Voorde J et al (2002) Effects of connexinmimetic peptides on nitric oxide synthase- and cyclooxygenaseindependent renal vasodilation. Kidney Int 61(1):177-185 
De Vuyst E, Decrock E et al (2006) Intracellular calcium changes trigger connexin32 hemichannel opening. EMBO J 25(1):34-44

De Vuyst E, Decrock E et al (2007) Connexin hemichannels and gap junction channels are differentially influenced by lipopolysaccharide and basic fibroblast growth factor. Mol Biol Cell 18(1): $34-46$

De Vuyst E, Wang $\mathrm{N}$ et al (2009) $\mathrm{Ca}^{2+}$ regulation of connexin43 hemichannels in C6 glioma and glial cells. Cell Calcium 46(3): $176-187$

De Vuyst E, Boengler K et al (2011) Pharmacological modulation of connexin-formed channels in cardiac pathophysiology. $\mathrm{Br} \mathrm{J}$ Pharmacol 163(3):469-483

Decrock E, De Vuyst E et al (2009a) Connexin43 hemichannels contribute to the propagation of apoptotic cell death in a rat C6 glioma cell model. Cell Death Differ 16(1):151-163

Decrock E, Vinken M et al (2009b) Connexin-related signaling in cell death: to live or let die? Cell Death Differ 16(4):524-536

Decrock E, Vinken $M$ et al (2011) Calcium and connexin-based intercellular communication, a deadly catch? Cell Calcium 50 (3):310-321

Delmar M, Coombs W et al (2004) Structural bases for the chemical regulation of connexin43 channels. Cardiovasc Res 62(2): 268-275

Desplantez T, Verma V et al (2012) Gap26, a connexin mimetic peptide, inhibits currents carried by connexin 43 hemichannels and gap junction channels. Pharmacol Res 65(5):546-552

D'Hondt C, Ponsaerts R et al (2009) Pannexins, distant relatives of the connexin family with specific cellular functions? Bioessays 31(9):953-974

D'Hondt C, Ponsaerts R et al (2011) Pannexin channels in ATP release and beyond: an unexpected rendezvous at the endoplasmic reticulum. Cell Signal 23(2):305-316

Dora KA, Martin PE et al (1999) Role of heterocellular gap junctional communication in endothelium-dependent smooth muscle hyperpolarization: inhibition by a connexin-mimetic peptide. Biochem Biophys Res Commun 254(1):27-31

Ebihara L, Steiner E (1993) Properties of a nonjunctional current expressed from a rat connexin46 cDNA in Xenopus oocytes. J Gen Physiol 102(1):59-74

Ek-Vitorin JF, Burt JM (2012) Structural basis for the selective permeability of channels made of communicating junction proteins. Biochim Biophys Acta (in press)

Eltzschig HK, Eckle T et al (2006) ATP release from activated neutrophils occurs via connexin 43 and modulates adenosinedependent endothelial cell function. Circ Res 99(10):1100-1108

Evans WH, Boitano S (2001) Connexin mimetic peptides: specific inhibitors of gap-junctional intercellular communication. Biochem Soc Trans 29(Pt 4):606-612

Evans WH, De Vuyst E et al (2006) The gap junction cellular internet: connexin hemichannels enter the signalling limelight. Biochem J 397(1):1-14

Flores CE, Nannapaneni S et al (2012) Trafficking of gap junction channels at a vertebrate electrical synapse in vivo. Proc Natl Acad Sci USA 109(9):E573-E582

Froger N, Orellana JA et al (2010) Inhibition of cytokine-induced connexin 43 hemichannel activity in astrocytes is neuroprotective. Mol Cell Neurosci 45(1):37-46

Gomes P, Srinivas SP et al (2005) ATP-dependent paracrine intercellular communication in cultured bovine corneal endothelial cells. Invest Ophthalmol Vis Sci 46(1):104-113

Goodenough DA, Paul DL (2003) Beyond the gap: functions of unpaired connexon channels. Nat Rev Mol Cell Biol 4(4):285-294

Goodenough DA, Paul DL (2009) Gap junctions. Cold Spring Harb Perspect Biol 1(1):a002576
Goodenough DA, Paul DL et al (1988) Topological distribution of two connexin32 antigenic sites in intact and split rodent hepatocyte gap junctions. J Cell Biol 107(5):1817-1824

Hagen A, Dietze A et al (2009) Human cardiac gap-junction coupling: effects of antiarrhythmic peptide AAP10. Cardiovasc Res 83(2): $405-415$

Harris AL (2001) Emerging issues of connexin channels: biophysics fills the gap. Q Rev Biophys 34(3):325-472

Harris A, Locke D (eds) (2009) Connexins: a guide. Springer, New York

Hawat G, Benderdour M et al (2010) Connexin43 mimetic peptide Gap26 confers protection to intact heart against myocardial ischemia injury. Pflugers Arch 460(3):583-592

Hennan JK, Swillo RE et al (2009) GAP-134 ([2S,4R]-1-[2-aminoacetyl]4-benzamidopyrrolidine-2-carboxylic acid) prevents spontaneous ventricular arrhythmias and reduces infarct size during myocardial ischemia/reperfusion injury in open-chest dogs. J Cardiovasc Pharmacol Ther 14(3):207-214

Herve JC, Dhein S (2010) Peptides targeting gap junctional structures. Curr Pharm Des 16(28):3056-3070

Herve JC, Derangeon M et al (2011) Gap junctional channels are parts of multiprotein complexes. Biochim Biophys Acta 1818(8): $1844-1865$

Hirst-Jensen BJ, Sahoo P et al (2007) Characterization of the $\mathrm{pH}$-dependent interaction between the gap junction protein connexin43 carboxyl terminus and cytoplasmic loop domains. J Biol Chem 282(8):5801-5813

Huang C, Han X et al (2012) Critical role of connexin43 in secondary expansion of traumatic spinal cord injury. J Neurosci 32(10): 3333-3338

Hunter AW, Barker RJ et al (2005) Zonula occludens-1 alters connexin43 gap junction size and organization by influencing channel accretion. Mol Biol Cell 16(12):5686-5698

Hutcheson IR, Chaytor AT et al (1999) Nitric oxide-independent relaxations to acetylcholine and A23187 involve different routes of heterocellular communication. Role of gap junctions and phospholipase $A_{2}$. Circ Res 84(1):53-63

Isakson BE, Evans WH et al (2001) Intercellular $\mathrm{Ca}^{2+}$ signaling in alveolar epithelial cells through gap junctions and by extracellular ATP. Am J Physiol Lung Cell Mol Physiol 280(2):L221L228

Isakson BE, Seedorf GJ et al (2003) Cell-cell communication in heterocellular cultures of alveolar epithelial cells. Am J Respir Cell Mol Biol 29(5):552-561

Ishikawa M, Iwamoto T et al (2011) Pannexin3 functions as an ER $\mathrm{Ca}^{2+}$ channel, hemichannel, and gap junction to promote osteoblast differentiation. J Cell Biol 193(7):1257-1274

Jarver P, Langel U (2006) Cell-penetrating peptides-a brief introduction. Biochim Biophys Acta 1758(3):260-263

Jiang S, Yuan H et al (2011) Glutamate release through connexin43 by cultured astrocytes in a stimulated hypertonicity model. Brain Res 1392:8-15

Juszczak GR, Swiergiel AH (2009) Properties of gap junction blockers and their behavioural, cognitive and electrophysiological effects: animal and human studies. Prog Neuropsychopharmacol Biol Psychiatry 33(2):181-198

Kameritsch P, Pogoda K et al (2011) Channel-independent influence of connexin 43 on cell migration. Biochim Biophys Acta 1818 (8):1993-2001

Kang J, Kang N et al (2008) Connexin43 hemichannels are permeable to ATP. J Neurosci 28(18):4702-4711

Karpuk N, Burkovetskaya M et al (2011) Neuroinflammation leads to region-dependent alterations in astrocyte gap junction communication and hemichannel activity. J Neurosci 31(2):414-425 
Kjenseth A, Fykerud TA et al (2012) The gap junction channel protein connexin 43 is covalently modified and regulated by SUMOylation. J Biol Chem 287(19):15851-15861

Kwak BR, Jongsma HJ (1999) Selective inhibition of gap junction channel activity by synthetic peptides. J Physiol 516(Pt 3): 679-685

Lai A, Le DN et al (2006) Oculodentodigital dysplasia connexin43 mutations result in non-functional connexin hemichannels and gap junctions in C6 glioma cells. J Cell Sci 119(Pt 3):532-541

Laird DW (2006) Life cycle of connexins in health and disease. Biochem J 394(Pt 3):527-543

Lewandowski R, Procida K et al (2008) RXP-E: a connexin43binding peptide that prevents action potential propagation block. Circ Res 103(5):519-526

Li H, Liu TF et al (1996) Properties and regulation of gap junctional hemichannels in the plasma membranes of cultured cells. J Cell Biol 134(4):1019-1030

Liu F, Arce FT et al (2006) Nanomechanics of hemichannel conformations: connexin flexibility underlying channel opening and closing. J Biol Chem 281(32):23207-23217

Maeda S, Nakagawa S et al (2009) Structure of the connexin26 gap junction channel at 3.5 A resolution. Nature 458(7238):597-602

Malchow RP, Qian H et al (1993) Evidence for hemi-gap junctional channels in isolated horizontal cells of the skate retina. J Neurosci Res 35(3):237-245

Matchkov VV, Rahman A et al (2006) Analysis of effects of connexin-mimetic peptides in rat mesenteric small arteries. Am J Physiol Heart Circ Physiol 291(1):H357-H367

Mendoza-Naranjo A, Bouma G et al (2011) Functional gap junctions accumulate at the immunological synapse and contribute to $\mathrm{T}$ cell activation. J Immunol 187(6):3121-3132

Myllykoski M, Kuczera K et al (2009) Complex formation between calmodulin and a peptide from the intracellular loop of the gap junction protein connexin43: molecular conformation and energetics of binding. Biophys Chem 144(3):130-135

O'Carroll SJ, Alkadhi M et al (2008) Connexin43 mimetic peptides reduce swelling, astrogliosis, and neuronal cell death after spinal cord injury. Cell Commun Adhes 15(1):27-42

O'Quinn MP, Palatinus JA et al (2011) A peptide mimetic of the connexin43 carboxyl terminus reduces gap junction remodeling and induced arrhythmia following ventricular injury. Circ Res 108(6):704-715

Orellana JA, Froger N et al (2011) ATP and glutamate released via astroglial connexin43 hemichannels mediate neuronal death through activation of pannexin 1 hemichannels. J Neurochem 118(5):826-840

Orellana JA, Saez PJ et al (2012a) Glucose increases intracellular free $\mathrm{Ca}^{2+}$ in tanycytes via ATP released through connexin43 hemichannels. Glia 60(1):53-68

Orellana JA, Sanchez HA et al (2012b) Regulation of intercellular calcium signaling through calcium interactions with connexinbased channels. Adv Exp Med Biol 740:777-794

Oshima A, Tani K et al (2011) Asymmetric configurations and $\mathrm{N}$-terminal rearrangements in connexin26 gap junction channels. J Mol Biol 405(3):724-735

Oviedo-Orta E, Gasque P et al (2001) Immunoglobulin and cytokine expression in mixed lymphocyte cultures is reduced by disruption of gap junction intercellular communication. FASEB J 15(3):768-774

Oviedo-Orta E, Errington RJ et al (2002) Gap junction intercellular communication during lymphocyte transendothelial migration. Cell Biol Int 26(3):253-263

Oviedo-Orta E, Perreau M et al (2010) Control of the proliferation of activated $\mathrm{CD} 4^{+}$T cells by connexins. J Leukoc Biol 88(1):79-86
Paemeleire K, Martin PE et al (2000) Intercellular calcium waves in HeLa cells expressing GFP-labeled connexin43, 32, or 26. Mol Biol Cell 11(5):1815-1827

Palatinus JA, Rhett JM et al (2011) The connexin43 carboxyl terminus and cardiac gap junction organization. Biochim Biophys Acta 1818(8):1831-1843

Parthasarathi K, Ichimura H et al (2006) Connexin43 mediates spread of $\mathrm{Ca}^{2+}$-dependent proinflammatory responses in lung capillaries. J Clin Invest 116(8):2193-2200

Pearson RA, Dale N et al (2005) ATP released via gap junction hemichannels from the pigment epithelium regulates neural retinal progenitor proliferation. Neuron 46(5):731-744

Pollok S, Pfeiffer AC et al (2011) Connexin43 mimetic peptide Gap27 reveals potential differences in the role of $\mathrm{Cx} 43$ in wound repair between diabetic and non-diabetic cells. J Cell Mol Med 15(4):861-873

Ponsaerts R, De Vuyst E et al (2010) Intramolecular loop/tail interactions are essential for connexin43-hemichannel activity. FASEB J 24(11):4378-4395

Ponsaerts R, Wang $\mathrm{N}$ et al (2012) The contractile system as a negative regulator of the connexin43 hemichannel. Biol Cell 104(7): 367-377

Rahman S, Carlile G et al (1993) Assembly of hepatic gap junctions. Topography and distribution of connexin 32 in intracellular and plasma membranes determined using sequence-specific antibodies. J Biol Chem 268(2):1260-1265

Retamal MA, Cortes CJ et al (2006) S-Nitrosylation and permeation through connexin 43 hemichannels in astrocytes: induction by oxidant stress and reversal by reducing agents. Proc Natl Acad Sci USA 103(12):4475-4480

Rhett JM, Gourdie RG (2012) The perinexus: a new feature of Cx43 gap junction organization. Heart Rhythm 9(4):619-623

Ring S, Karakhanova S et al (2010) Gap junctions between regulatory $\mathrm{T}$ cells and dendritic cells prevent sensitization of $\mathrm{CD} 8^{+} \mathrm{T}$ cells. J Allergy Clin Immunol 125(1):237-246

Robertson J, Lang S et al (2010) Peptidoglycan derived from Staphylococcus epidermidis induces connexin 43 hemichannel activity with consequences on the innate immune response in endothelial cells. Biochem J 432(1):133-143

Rottlaender D, Boengler K et al (2012) Glycogen synthase kinase 3 beta transfers cytoprotective signaling through connexin 43 onto mitochondrial ATP-sensitive $\mathrm{K}^{+}$channels. Proc Natl Acad Sci USA 109(5):E242-E251

Saez JC, Retamal MA et al (2005) Connexin-based gap junction hemichannels: gating mechanisms. Biochim Biophys Acta 1711 (2):215-224

Saez JC, Schalper KA et al (2010) Cell membrane permeabilization via connexin hemichannels in living and dying cells. Exp Cell Res 316(15):2377-2389

Samoilova M, Wentlandt K et al (2008) Connexin43 mimetic peptides inhibit spontaneous epileptiform activity in organotypic hippocampal slice cultures. Exp Neurol 210(2):762-775

Sarieddine MZ, Scheckenbach KE et al (2009) Connexin43 modulates neutrophil recruitment to the lung. J Cell Mol Med 13(1112):4560-4570

Sato PY, Coombs W et al (2011) Interactions between ankyrin-G, plakophilin-2, and connexin43 at the cardiac intercalated disc. Circ Res 109(2):193-201

Scemes E, Spray DC et al (2009) Connexins, pannexins, innexins: novel roles of "hemi-channels". Pflugers Arch 457(6):12071226

Schalper KA, Riquelme MA et al (2012) Modulation of gap junction channels and hemichannels by growth factors. Mol Biosyst 8(3):685-698 
Scott CA, Kelsell DP (2011) Key functions for gap junctions in skin and hearing. Biochem J 438(2):245-254

Shibayama J, Lewandowski R et al (2006) Identification of a novel peptide that interferes with the chemical regulation of connexin43. Circ Res 98(11):1365-1372

Shintani-Ishida K, Uemura K et al (2007) Hemichannels in cardiomyocytes open transiently during ischemia and contribute to reperfusion injury following brief ischemia. Am J Physiol Heart Circ Physiol 293(3):H1714-H1720

Solan JL, Lampe PD (2009) Connexin43 phosphorylation: structural changes and biological effects. Biochem J 419(2):261-272

Sood A, Salih S et al (2011) Signalling of DNA damage and cytokines across cell barriers exposed to nanoparticles depends on barrier thickness. Nat Nanotechnol 6(12):824-833

Sosinsky GE, Nicholson BJ (2005) Structural organization of gap junction channels. Biochim Biophys Acta 1711(2):99-125

Sosinsky GE, Solan JL et al (2007) The C-terminus of connexin43 adopts different conformations in the Golgi and gap junction as detected with structure-specific antibodies. Biochem J 408(3): 375-385

Spray DC, Ye ZC et al (2006) Functional connexin "hemichannels": a critical appraisal. Glia 54(7):758-773

Srisakuldee W, Jeyaraman MM et al (2009) Phosphorylation of connexin-43 at serine 262 promotes a cardiac injury-resistant state. Cardiovasc Res 83(4):672-681

Stehberg J, Moraga-Amaro R, Salazar C, Becerra A, Echeverría C, Orellana JA, Bultynck G, Ponsaerts R, Leybaert L, Simon F, Sáez JC, Retamal MA (2012) Release of gliotransmitters through astroglial connexin 43 hemichannels is necessary for fear memory consolidation in the basolateral amygdala. FASEB J. doi:10.1096/fj.11-198416

Stong BC, Chang Q et al (2006) A novel mechanism for connexin26 mutation linked deafness: cell death caused by leaky gap junction hemichannels. Laryngoscope 116(12):2205-2210

Sun JD, Liu Y et al (2012) Gap junction dysfunction in the prefrontal cortex induces depressive-like behaviors in rats. Neuropsychopharmacology 37(5):1305-1320

Thimm J, Mechler A et al (2005) Calcium-dependent open/closed conformations and interfacial energy maps of reconstituted hemichannels. J Biol Chem 280(11):10646-10654

Vaiyapuri S, Jones CI et al (2012) Gap junctions and connexin hemichannels underpin hemostasis and thrombosis. Circulation 125(20):2479-2491
Verma V, Larsen BD et al (2009a) Novel pharmacophores of connexin43 based on the "RXP" series of Cx43-binding peptides. Circ Res 105(2):176-184

Verma V, Hallett MB et al (2009b) Perturbing plasma membrane hemichannels attenuates calcium signalling in cardiac cells and HeLa cells expressing connexins. Eur J Cell Biol 88(2):79-90

Wang J, Ma M et al (2007) "Modulation of membrane channel currents by gap junction protein mimetic peptides: size matters. Am J Physiol Cell Physiol 293(3):C1112-C1119

Warner A, Clements DK et al (1995) Specific motifs in the external loops of connexin proteins can determine gap junction formation between chick heart myocytes. J Physiol 488(Pt 3):721-728

Wright CS, van Steensel MA et al (2009) Connexin mimetic peptides improve cell migration rates of human epidermal keratinocytes and dermal fibroblasts in vitro. Wound Repair Regen 17(2):240249

Wright CS, Pollok S et al (2012a) The connexin mimetic peptide Gap27 increases human dermal fibroblast migration in hyperglycemic and hyperinsulinemic conditions in vitro. J Cell Physiol 227(1):77-87

Wright JA, Richards T, Becker DL (2012b) Connexins and diabetes. Cardiol Res Pract 2012:496904

Xing D, Kjolbye AL et al (2003) ZP123 increases gap junctional conductance and prevents reentrant ventricular tachycardia during myocardial ischemia in open chest dogs. J Cardiovasc Electrophysiol 14(5):510-520

Yang J, Darley RL et al (2009) Low connexin channel-dependent intercellular communication in human adult hematopoietic progenitor/stem cells: probing mechanisms of autologous stem cell therapy. Cell Commun Adhes 16(5-6):138-145

Yoon JJ, Green CR et al (2010) Dose-dependent protective effect of connexin43 mimetic peptide against neurodegeneration in an ex vivo model of epileptiform lesion. Epilepsy Res 92(2-3):153162

Zhou Y, Yang W et al (2007) Identification of the calmodulin binding domain of connexin 43. J Biol Chem 282(48):35005-35017

Zimmer DB, Green CR et al (1987) Topological analysis of the major protein in isolated intact rat liver gap junctions and gap junction-derived single membrane structures. J Biol Chem 262 (16):7751-7763 